\title{
BMJ Open The role of nurse specialists in the delivery of integrated diabetes care: a cross-sectional survey of diabetes nurse specialist services
}

\author{
Fiona Riordan, ${ }^{1}$ Sheena M McHugh, ${ }^{1}$ Katie Murphy, ${ }^{2}$ Julie Barrett, ${ }^{1}$ \\ Patricia M Kearney ${ }^{1}$
}

To cite: Riordan F, McHugh SM, Murphy $\mathrm{K}$, et al. The role of nurse specialists in the delivery of integrated diabetes care: a cross-sectional survey of diabetes nurse specialist services. BMJ Open 2017;7:e015049. doi:10.1136/ bmjopen-2016-015049

\section{- Prepublication history and} additional material for this paper are available online. To view these files please visit the journal online (http://dx.doi. org/10.1136/bmjopen-2016015049).

Received 7 November 2016 Revised 26 January 2017 Accepted 2 February 2017

CrossMark

${ }^{1}$ Department of Epidemiology and Public Health, University College Cork National University of Ireland, Cork, Ireland ${ }^{2}$ Department of General Practice, University College Cork, Cork, Ireland

\section{Correspondence to}

Fiona Riordan;

fiona.riordan@ucc.ie and

Professor Patricia M Kearney;

patricia.kearney@ucc.ie

\section{ABSTRACT}

Objectives International evidence suggests the diabetes nurse specialist (DNS) has a key role in supporting integrated management of diabetes. We examine whether hospital and community DNS currently support the integration of care, examine regional variation in aspects of the service relevant to the delivery of integrated care and identify barriers to service delivery and areas for improvement.

Design A cross-sectional survey of hospital and community-based DNS in Ireland.

Methods Between September 2015 and April 2016, a 67 item online survey, comprising closed and open questions on their clinical role, diabetes clinics, multidisciplinary working, and barriers and facilitators to service delivery, was administered to all eligible DNS $(n=152)$ in Ireland. DNS were excluded if they were retired or on maternity leave or extended leave.

Results The response rate was $66.4 \%(n=101): 60.6 \%$ $(n=74)$ and $89.3 \%(n=25)$ among hospital and community DNS, respectively. Most DNS had patients with stable (81.8\%) and complicated type 2 diabetes mellitus (89.9\%) attending their service. The majority were delivering nurseled clinics $(81.1 \%)$. Almost all DNS had a role liaising with (91\%), and providing support and education to (95\%), other professionals. However, only a third reported that there was local agreement on how their service should operate between the hospital and primary care. Barriers to service delivery that were experienced by DNS included deficits in the availability of specialist staff (allied health professionals, endocrinologists and DNS), insufficient space for clinics, structured education and issues with integration.

Conclusions Delivering integrated diabetes care through a nurse specialist-led approach requires that wider service issues, including regional disparities in access to specialist resources and formalising agreements and protocols on multidisciplinary working between settings, be explicitly addressed.

\section{BACKGROUND}

In recent years, internationally and in Ireland, there has been increased interest in how to deliver integrated care for people
Strengths and limitations of this study

- This study is the first to examine the provision of diabetes nurse specialist (DNS) services nationally in Ireland.

- A comprehensive questionnaire that was employed in a previous UK study and adapted for the Irish context was used for the study.

- Although the support of the Irish Diabetes Nurse Specialist Association and other sources was enlisted to generate the sampling frame, there is no definitive list of all DNS in Ireland.

- Only a small number of nurses work in both hospital and community roles; therefore, we did not distinguish between DNS who are solely based in the community and those in new posts working between hospital and community.

with chronic diseases such as type 2 diabetes mellitus (T2DM), ${ }^{12}$ coordinating management so that patients receive the 'right services' in the 'right place'. ${ }^{3}$ The complex nature of diabetes necessitates the involvement of healthcare professionals from different disciplines and settings to achieve effective management. ${ }^{2}$ Integrated diabetes management across community-based and specialist services has been shown to improve quality of care $^{45}$ and reduce preventable hospitalisations for diabetes-related complications. $^{6}$

International evidence suggests the nurse specialist has a key role in supporting the integrated management of chronic disease ${ }^{7}$ through delivering nurse-led clinics in primary care ${ }^{89}$ liaising between care providers ${ }^{5-11}$ and providing specialist education and support to other professionals, ${ }^{5}{ }^{10}$ including those in primary care..$^{9} 12$ 13 The shift towards primary care management of T2DM has meant the role has been increasingly moved into community settings. ${ }^{14}$ The $\mathrm{UK}^{13}$ and the 
Netherlands ${ }^{58}$ have seen the introduction of models of care where the diabetes nurse specialist (DNS) supports general practitioners (GPs) or practice nurses (PNs) in diabetes management ${ }^{813}$ (eg, intermediate care clinics for diabetes (ICCD), which accept referrals of more complex patients to reduce the burden to the hospital system ${ }^{15}$ ), or performs tasks previously conducted by the GP, including coordination and organisation of care (vertical task substitution). ${ }^{8}$ These models have been found to improve clinical outcomes, ${ }^{58}$ reduce inappropriate referrals to secondary care, ${ }^{13}$ and may reduce outpatient attendances. ${ }^{15}{ }^{16}$ However, the role and work setting of DNS differ between countries. ${ }^{17-19}$ For example, in Sweden and the Netherlands, half or more of DNS may work in integrated or community settings and have prescribing rights. ${ }^{11} 17$ In contrast, most DNS in Ireland are hospital-based, and although nurse prescribing has been introduced since 2008, not all nurses perform this role. Given these differences, it is important to establish how the DNS role within the specific health system supports an integrated and sustainable model of diabetes care.

In Ireland, the importance of nurse specialists in chronic disease management and facilitating integrated care between settings has been recognised. ${ }^{20-22}$ The National Clinical Programme for Diabetes (NCPD), established in 2010 to improve care for people with diabetes in Ireland, is developing the DNS service by introducing more community-based DNS to facilitate the delivery of a new model of integrated diabetes care. ${ }^{23}$ These changes are taking place within a traditionally hospital-centric healthcare system where there is a disconnect between secondary and primary care services in how they are funded, managed and resourced. Diabetes services have historically been unstructured and characterised by pockets of good provision and a mix of care arrangements. ${ }^{20}$ In some areas diabetes care is primarily hospital-led; in others, care is delivered in general practice, sometimes on an opportunistic and ad-hoc basis. Chronic disease management in secondary care is also not well integrated with general practice, ${ }^{22}$ not all areas have a local diabetes service, and within general practice the delivery of diabetes care may be variable. In many areas, there are deficiencies in terms of access to specialist resources, including DNS. ${ }^{24-26}$ This has driven the development of formal diabetes initiatives (10 nationally) that seek to improve the quality and organisation of care at a local level. These include models of structured or shared care with local clinical guidelines and support from a community DNS to facilitate communication between these practices and the hospital, ${ }^{9}$ or enhanced access to specialist community resources, including dietetics, podiatry and DNS. ${ }^{27}$

The purpose of the new integrated care model is to standardise management of diabetes. It aims to ensure patients are cared for in the most appropriate setting and by the most appropriate healthcare professionals. As outlined in the latest guidance on diabetes management, ${ }^{28}$ patients with uncomplicated T2DM are managed in primary care, patients with complicated T2DM are managed between primary and secondary care, and management of type 1 diabetes mellitus (T1DM) and gestational diabetes mellitus (GDM) takes place in secondary care. Implementation of the new model may vary depending on local circumstances and context, including existing models of care. Newly introduced DNS have, in some areas, been linked to existing initiatives, whereas in other areas the service was entirely new. The current study may identify some of these regional variations and forms part of a programme of work evaluating the implementation of the NCPD. ${ }^{29}$

The new reforms can be understood as evidence-based strategies to integrate care at the level of service organisation and delivery (eg, promoting multidisciplinary teamwork through establishing the DNS as a 'link' between services; providing dedicated support by nurse specialists to primary care professionals) and at the clinical level (eg, introduction of guidelines on practice management). ${ }^{28}$ Similar to the ICCDs established in the UK, these new DNS will provide necessary intermediary specialist support in the community in the management of more complex patients. They provide education and support for GPs and PNs, and work between community $(80 \%)$ and hospital settings $(20 \%)$, facilitating integration between the two settings. ${ }^{28}$ DNS may deliver clinics in general practice, independently, or in some cases initially jointly with the PN or GP, to build capacity, confidence and skills in the management of more uncomplicated patients.

Although DNS support for patients and health professionals is a pillar of the national strategy for delivering integrated diabetes care, unlike other countries, ${ }^{5} 10111930$ there is a dearth of information on how DNS services are delivered in Ireland. Our aim is to examine the way and extent to which DNS services currently support the integration of care and identify areas for improvement. We expect hospital and community DNS to differ in terms of the patients they provide care to and the professionals they support and are supported by. Therefore we describe the role of these DNS separately. Given the current variation in how diabetes services are delivered in Ireland, some aspects of the DNS role that are important in the integration of care (nurse-led clinics, agreements on working across primary and secondary care, access to other professionals) may differ across the country. Therefore, we examine these by region. Finally, we identify barriers and facilitators to delivering diabetes care from the DNS perspective. The study will provide an insight into how the DNS role works in the context of a traditionally fragmented health system characterised by regional variation and ongoing efforts to standardise and improve how diabetes care is delivered. ${ }^{23}$

\section{METHODS}

\section{Participants}

The eligible study population comprised all currently employed DNS ( $\mathrm{n}=152)$, excluding retired DNS, those on maternity or extended leave. Registration with the Irish Diabetes Nurse Specialist Association (IDNSA) is not mandatory, and there is no national register of DNS posts 
in Ireland. Therefore, we compiled a list through regional primary care initiatives, IDNSA, Diabetes Ireland, the national diabetes charity which funds the provision of some DNS posts, and the NCPD, which highlighted the survey at national and local conferences and meetings. The IDNSA asked their members to register their details with the study researchers.

\section{Questionnaire}

Participants were invited by e-mail to complete the self-administered, 67-item questionnaire electronically (SurveyMonkey) between September 2015 and April 2016. The survey was based on a questionnaire developed by Diabetes UK and Association of British Clinical Diabetologists (ABCD) Specialist Services Study Group, ${ }^{19}$ modified for the Irish health system in collaboration with a local nurse network, and piloted with two DNS, both of whom worked across hospital and community settings. Adaptations related to the questionnaire are included as online supplementary material. The survey comprised closed and open-ended questions addressing the DNS' role in diabetes, clinic activity, links with other services, the nature of service agreements and their liaison role, and barriers and facilitators to service delivery (online supplementary material). Three reminders were sent, the final in conjunction with an e-mail notification from the IDNSA (online supplementary material).

\section{Data management and analysis}

Data were cleaned in Excel before importing into Stata (SE V.12) for analysis. Fisher's exact tests were used to test differences in the role performed between hospital and community, and to examine service provision (clinics, referrals, local agreements) across the four regions defined according to the Diabetes Services Implementation Groups (DSIG), which are clinically led regional networks responsible for local implementation of the national programme. A $p$ value of $<0.05$ was considered statistically significant. The Bonferroni correction was used to adjust for multiple comparisons. Complete case analysis was used and missing data are highlighted as applicable. NVivo (V.11) was used to manage and categorise open-ended responses. FR conducted a thematic analysis of responses to the questions on barriers and facilitators. The grouping of codes to generate overarching themes was reviewed by JB.

\section{RESULTS}

The response rate was $66.4 \% \quad(\mathrm{n}=101): 60.6 \% \quad(\mathrm{n}=74)$ of hospital and $89.3 \%(\mathrm{n}=25)$ of community DNS. This included six advanced nurse practitioner or advanced midwife practitioner grade nurses, two clinical nurse managers, and three diabetes nurses not graded as DNS but who were qualified and performing the role of DNS. Two DNS in non-clinical roles were classified as 'Other'. DNS from all four DSIGs and all counties in the Ireland participated. Most were hospital-based (table 1).
Table 1 Characteristics of the sample population $(n=101)$

\begin{tabular}{|c|c|}
\hline & N (\%) \\
\hline \multicolumn{2}{|l|}{ Based } \\
\hline Hospital & $74(73.3)^{\star}$ \\
\hline Community & $25(24.8)^{\dagger}$ \\
\hline Other & $2(2.0)$ \\
\hline \multicolumn{2}{|l|}{ Service area } \\
\hline Adult & $66(65.4)$ \\
\hline Paediatric only & $14(13.9)$ \\
\hline Maternity only & $5(5.0)$ \\
\hline All three service areas & $9(8.9)$ \\
\hline Adult and paediatrics & $3(3.0)$ \\
\hline Adult and maternity & $2(2.0)$ \\
\hline Other & $2(2.0)$ \\
\hline \multicolumn{2}{|l|}{ Region } \\
\hline 1 & $23(22.8)$ \\
\hline 2 & $25(24.8)$ \\
\hline 3 & $27(26.7)$ \\
\hline 4 & $26(25.7)$ \\
\hline \multicolumn{2}{|l|}{ Age } \\
\hline $25-34$ & $9(8.9)$ \\
\hline $35-44$ & $36(35.6)$ \\
\hline $45-54$ & $38(37.6)$ \\
\hline $55-64$ & $18(17.8)$ \\
\hline \multicolumn{2}{|l|}{ Education } \\
\hline Masters in diabetes & $11(10.9)$ \\
\hline Diabetes counselling course & $7(6.9)$ \\
\hline PGDip in diabetes nursing & $81(80.2)$ \\
\hline $\begin{array}{l}\text { Certificate in diabetes nursing (including } \\
\text { e-learning) }\end{array}$ & $22(21.8)$ \\
\hline Masters in primary care & $1(1.0)$ \\
\hline Registered nurse prescriber & $37(36.6)$ \\
\hline \multicolumn{2}{|l|}{ Employer $^{\ddagger}$} \\
\hline Health Service Executive & $84(83.1)$ \\
\hline Private & $9(8.9)$ \\
\hline Other & $6(5.9)$ \\
\hline Employment & Mean (SD) \\
\hline Years working as a DNS $\S$ & $11.2(7.4)$ \\
\hline Years in current position" & $8.1(6.8)$ \\
\hline
\end{tabular}

*Includes six advanced nurse practitioner or advanced midwife practitioner grade nurses, two clinical nurse managers, and three diabetes nurses not graded as DNS but qualified and performing role of DNS.

†Includes 16 integrated care nurses recruited as part of the national programme.

¥Missing data for two respondents.

§Missing data for three respondents.

१Missing data for one respondent.

DNS, diabetes nurse specialist. 
Respondents were working as a DNS for an average of 11 years. Although most had completed a postgraduate diploma in diabetes, few $(10.9 \%)$ had a master's-level qualification, and just over a third $(36.6 \%)$ were nurse prescribers.

\section{DNS role}

Most DNS had a written job description ( $\mathrm{n}=89,88.1 \%)$. All DNS were involved in some aspect of patient management (table 2), but this differed by setting. More hospital than community DNS were involved in inpatient care, and specific elements of care for patients with T1DM (referrals, glucose monitoring, insulin initiation or education, checking injection sites $)(p<0.001)$ and provision of specialist clinics (non-significant) (table 2). While most hospital and community DNS reported that patients with complicated T2DM attended their service, the majority also saw patients with stable T2DM (figure 1). In two regions a greater proportion of nurses reported seeing stable T2DM (R1: 95.7\%; R2: 70.8\%; R3: 88.9\%; R4: $72 \%)$. Other patients seen were reported in open-ended comments (online supplementary material).

Of the $58(59.2 \%)$ DNS who spent time on administrative work, the mean hours per week were $4.8 \pm 2.5$ and $5.7 \pm 2.8$ among hospital and community DNS, respectively. Few spent time on research or audit $(n=36,35.6 \%)$; on average, hospital DNS spent $1.5 \pm 0.8$ hours per week while community DNS spent $2.3 \pm 1.6$ hours. Few DNS had a dedicated budget $(\mathrm{n}=16,16.3 \%)$ or protected time $(\mathrm{n}=27,27.5 \%)$ for continuing professional development (CPD).

\section{Clinics}

Nurse-led clinics can be understood as clinics where DNS may work without immediate supervision and are responsible for case management. Overall, $81.1 \%(n=82)$ of DNS delivered nurse-led clinics, including generalised clinics $(n=31,37.8 \%)$, specialised $(n=27,32.9 \%)$ or both $(\mathrm{n}=24,29.3 \%)$.

The greatest proportion of DNS provided $\geq 4$ clinics per week $(48.8 \%)$. While similar across most regions (R1: 55.6\%; R2: 61.9\%; R3: 54.6\%; R4: 23.8\%), frequency in R4 was consistently lower. This was true among both DNS types: overall $52 \%$ community DNS provided $\geq 4$ clinics (R1: 57.1\%; R2: 50\%; R3:8 0\% R4: 28.6\%) and $47.5 \%$ of hospital DNS provided $\geq 4$ clinics (R1: $54.5 \%$, R2: $64.7 \%$, R3: $47.1 \%$, R4: $21.4 \%$ ) (online supplementary material).

Some DNS were supported in clinics by other members of the multidisciplinary team, for example a podiatrist $(\mathrm{n}=30,36.6 \%)$ or dietician $(\mathrm{n}=44,53.7 \%)$. Most community DNS were supported in clinic by a PN (73.9\%). According to hospital and community DNS, patients generally saw a consultant $(74.6 \%)$ or GP $(56.5 \%)$ at a later date rather than on the day of the clinic.

Half reported a waiting list for their clinic service. Where reported $(n=41)$, the waiting time was commonly $1-3$ months $(n=20)$, ranging from $>1$ month $(n=5)$ to a year or more $(n=4)$. The main reasons reported in open-ended comments $(n=51)$ were the referral volume $(n=24)$ and shortage of clinical staff $(n=12)$. Of 24 respondents who provided clinics in the community, 12 reported that GPs were eligible to access those clinics, and in open-ended comments $(n=11)$ indicated the service was available to GPs who were enrolled in a shared or structured care scheme $(n=6)$, interested in diabetes care or willing to engage with the integrated care programme $(n=3)$, or those practices employing a PN $(n=2)$. Respondents reported that clinics were currently inaccessible where the service was at capacity or the catchment area was too large for the DNS to cover $(n=4)$.

\section{Links with other professionals}

Most DNS ( $\mathrm{n}=94,95 \%)$ were educating other professionals, primarily hospital-based nursing staff by hospital DNS (81.2\%), and PNs (92\%) and GPs (88\%) by community DNS. Community DNS were involved in education of allied health professionals (52\%) and staff in nursing homes $(21.6 \%)$ (table 2).

Most DNS liaised with other healthcare professionals $(\mathrm{n}=92,91.1 \%)$ (table 2). As outlined in open-ended responses $(n=83)$, this role involved patient case discussion $(\mathrm{n}=40)$ and follow-up $(\mathrm{n}=8)$, referrals (advising but also being able to facilitate fast-track into hospital) $(\mathrm{n}=18)$, providing advice $(\mathrm{n}=13)$ and education $(\mathrm{n}=7)$ to other staff, seeking advice from consultants $(n=6)$, and being a coordinator or 'link' between services $(n=10)$.

Over one third of DNS $(n=37,36.6 \%)$ reported there was no discharge pathway to primary care for ward discharges (R1: 30.4\%; R2: 40\%; R3: 44.4\%; R4: 30.8\%), and a third $(\mathrm{n}=36,36.7 \%)$ reported there was an agreement between the hospital and primary care outlining how their service operates (R1: 50\%; R2: 16.7\%; R3: 33.3\%; R4: 48\%). As outlined in open-ended comments $(\mathrm{n}=29)$ local agreements included following a shared care model $(n=6)$ or integrated model (regular GP review with annual secondary care review) $(n=5)$, working $80 / 20$ between community/hospital $(n=5)$, rapid referral pathways from primary care into hospital $(n=3)$ or being able to discharge patients to primary care $(n=2)$.

While almost all DNS reported referral access to other professionals $(\mathrm{n}=92,91.1 \%)$, there were regional differences in access to social workers $(p=0.01)$ and psychologists $(\mathrm{p}=0.01)$ (figure 2) (non-significant after adjustment).

\section{Barriers and facilitators to delivering diabetes care}

Most participants outlined barriers and facilitators to delivering their service in open-ended comments $(n=89$, $88 \%$ ). DNS suggested it was not feasible to conduct audit, research and quality improvement $(\mathrm{n}=14)$, citing time constraints $(n=7)$, and poor IT systems $(n=4)$ as the main reasons. They identified limited opportunities for professional development $(n=9)$, which was not supported by managers $(n=3)$ or allocated protected time $(n=3)$.

Being supported by the multidisciplinary team facilitated service delivery $(n=15)$, and DNS identified a 
Table 2 Specific roles performed by DNS

\begin{tabular}{|c|c|c|c|c|c|c|c|}
\hline & \multicolumn{2}{|c|}{ Overall $(n=99)^{*}$} & \multicolumn{2}{|c|}{ Hospital $(n=74)$} & \multicolumn{2}{|c|}{ Community (n=25) } & \\
\hline & $\begin{array}{l}\text { Type 1, N } \\
\text { (\%) }\end{array}$ & $\begin{array}{l}\text { Type 2, N } \\
(\%)\end{array}$ & $\begin{array}{l}\text { Type 1, N } \\
\text { (\%) }\end{array}$ & $\begin{array}{l}\text { Type 2, N } \\
\text { (\%) }\end{array}$ & Type 1, N (\%) & $\begin{array}{l}\text { Type 2, N } \\
\text { (\%) }\end{array}$ & \\
\hline \multicolumn{8}{|l|}{ Core role } \\
\hline Patient management $^{\dagger}$ & $88(88.9)$ & $90(90.9)$ & $73(98.6)$ & $67(90.5)$ & $15(60.0)$ & $23(92.0)$ & \\
\hline Medical review & $54(54.5)$ & $57(57.6)$ & 46 (62.2) & $44(59.5)$ & $8(32.0)$ & $13(52)$ & \\
\hline Telephone advice $^{\dagger}$ & 89 (89.9) & 89 (89.9) & $72(97.3)$ & $66(89.2)$ & $17(68.0)$ & $23(92.0)$ & \\
\hline Referrals & $73(73.7)$ & $74(74.7)$ & $62(83.8)$ & 57 (77.0) & $11(44.0)$ & 17 (68.0) & \\
\hline Dose adjustment & $73(73.7)$ & $72(72.7)$ & $58(78.4)$ & $51(68.9)$ & $15(60.0)$ & $21(84.0)$ & \\
\hline $\begin{array}{l}\text { Insulin/GLP (glucagon-like } \\
\text { peptide) initiation/education }^{\dagger}\end{array}$ & $81(81.8)$ & 89 (89.9) & 68 (91.9) & 66 (89.2) & $13(52)$ & 23 (92.0) & \\
\hline Checking injection sites $^{\dagger}$ & 90 (90.9) & 89 (89.9) & $73(98.6)$ & 66 (89.2) & $17(68)$ & $23(92.0)$ & \\
\hline Glucose monitoring $^{\dagger}$ & 89 (89.9) & $91(91.9)$ & $73(98.6)$ & $67(90.5)$ & $16(64.0)$ & $24(96.0)$ & \\
\hline Inpatient care ${ }^{\ddagger}$ & 77 (77.8) & $71(71.7)$ & 69 (93.2) & $61(82.4)$ & $8(32)$ & $10(40.0)$ & \\
\hline Hypo management $^{\dagger}$ & 89 (89.9) & $90(90.9)$ & $73(98.6)$ & $67(90.5)$ & $16(64)$ & $23(92.0)$ & \\
\hline \multicolumn{8}{|l|}{ Specialist roles } \\
\hline Hypertension clinics & $5(5.1)$ & $6(6.1)$ & $5(6.8)$ & $5(6.8)$ & $0(0)$ & $1(4.0)$ & \\
\hline Renal clinics & $10(10.1)$ & $13(13.1)$ & $10(13.5)$ & $12(16.2)$ & $0(0)$ & $1(4.0)$ & \\
\hline $\begin{array}{l}\text { Assessment clinics prior to } \\
\text { surgery }\end{array}$ & 25 (25.3) & 23 (23.2) & $23(31.1)$ & $21(28.4)$ & $2(8.0)$ & $2(8.0)$ & \\
\hline Preconception discussion & $52(52.5)$ & $48(48.5)$ & $41(55.4)$ & $36(48.6)$ & $11(44.0)$ & $12(48.0)$ & \\
\hline Prescribing & $31(31.3)$ & $34(34.3)$ & $27(36.5)$ & $29(39.4)$ & $4(16.0)$ & $5(20.0)$ & \\
\hline \multicolumn{8}{|l|}{ Other } \\
\hline Providing foot care & $76(76.7)$ & & $52(70.3)$ & & $24(96.0)$ & & \\
\hline RetinaScreen registration & $62(62.3)$ & & $43(58.1)$ & & $19(76.0)$ & & \\
\hline \multicolumn{8}{|l|}{ Liaison } \\
\hline Consultant & $81(81.8)$ & & $60(81.1)$ & & $21(84)$ & & \\
\hline Hospital DNS $\S$ & $43(43.4)$ & & $22(29.7)$ & & $21(84)$ & & \\
\hline Community DNS & $48(48.5)$ & & $40(54.1)$ & & $8(32)$ & & \\
\hline GP§ & $70(70.7)$ & & $46(62.2)$ & & $24(96)$ & & \\
\hline \multirow[t]{2}{*}{$\mathrm{PN}^{\S}$} & $58(58.6)$ & & $35(47.3)$ & & $23(92)$ & & \\
\hline & $\begin{array}{l}\text { Overall } \\
(\mathrm{n}=101)\end{array}$ & & $\begin{array}{l}\text { Hospital } \\
(\mathrm{n}=74)\end{array}$ & & $\begin{array}{l}\text { Community } \\
(\mathrm{n}=25)\end{array}$ & & $\begin{array}{l}\text { Other } \\
(n=2)\end{array}$ \\
\hline \multicolumn{8}{|l|}{ Professional education } \\
\hline $\mathrm{GP}^{\S}$ & $48(47.5)$ & & $25(33.8)$ & & $22(88.0)$ & & $1(50)$ \\
\hline $\mathrm{PN}^{\S}$ & $60(59.4)$ & & $35(47.3)$ & & $23(92.0)$ & & $2(100)$ \\
\hline Nursing staff in hospitals ${ }^{\S}$ & $82(81.2)$ & & $71(95.9)$ & & $11(44.0)$ & & $0(0)$ \\
\hline Medical staff in hospitals ${ }^{\S}$ & $49(48.5)$ & & $47(63.5)$ & & $2(8.0)$ & & $0(0)$ \\
\hline Allied health professionals & $41(40.6)$ & & $27(36.5)$ & & $13(52)$ & & $1(50)$ \\
\hline Medical staff in nursing homes ${ }^{\S}$ & $35(34.7)$ & & $16(21.6)$ & & $17(68.0)$ & & $2(100)$ \\
\hline Patient education & $101(100)$ & & $74(100)$ & & $25(100)$ & & $2(100)$ \\
\hline
\end{tabular}

*Two respondents were excluded as they did not perform a clinical role.

†Significant difference in role performed for patients with type 1 diabetes mellitus after adjustment for multiple comparisons (Bonferroni corrected, $p<0.002$ ).

$\ddagger$ Significant difference in role performed for patients with type 2 diabetes mellitus after adjustment for multiple comparisons (Bonferroni corrected, $p<0.002)$.

$\S S i g n i f i c a n t$ difference in role performed after adjustment for multiple comparisons (Bonferroni corrected, $p<0.002$ ).

DNS, diabetes nurse specialist; GP, general practitioner; PN, practice nurse. 


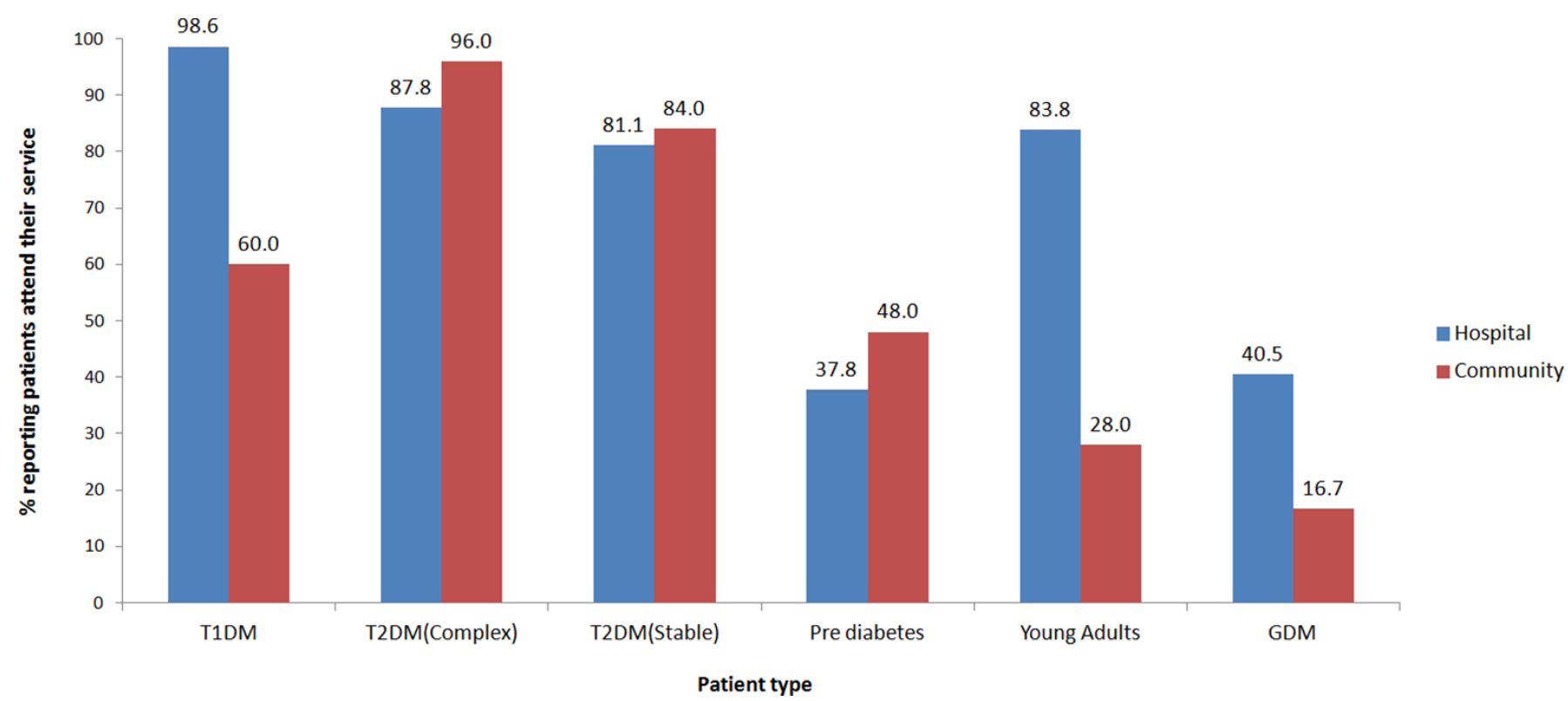

Figure 1 Patient types seen by nurse type: hospital $(n=74)$ or community $(n=25)$.

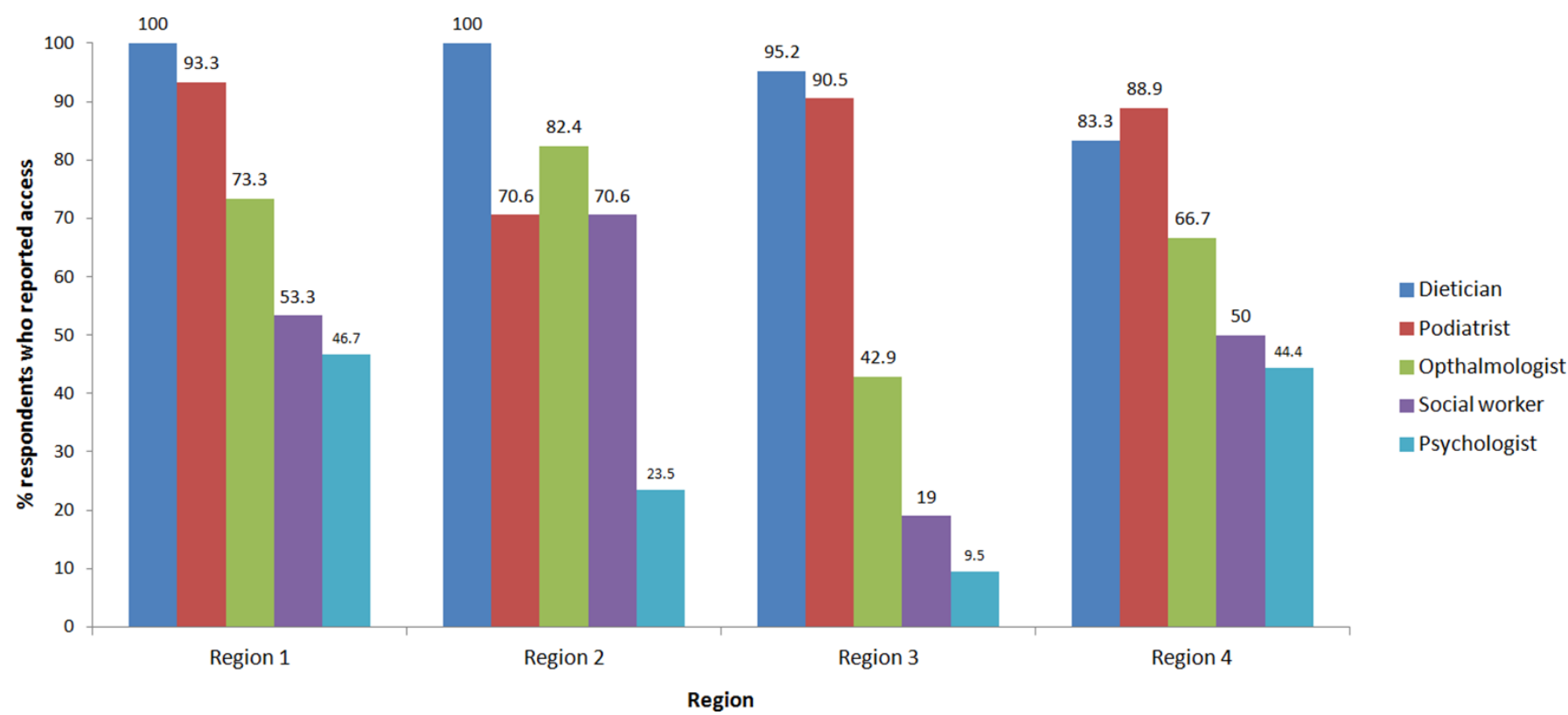

Figure 2 Referral access by region.

shortage of specialist staff (allied health professionals, endocrinologists, DNS) as a main barrier to providing care $(n=48)$. Other barriers were a lack of clerical support $(\mathrm{n}=19)$, poor ICT (information and communication technology) $(\mathrm{n}=8)$ and space limitations $(\mathrm{n}=19)$, which affected clinic $(\mathrm{n}=10)$ and structured education $(n=8)$ provision. Barriers to integration included inappropriate referrals of stable T2DM to secondary care $(n=7)$, GP reluctance to engage with the new community DNS service $(n=7)$ and the lack of ICT to facilitate information-sharing between primary and secondary care $(n=6)$.

\section{DISCUSSION}

Main findings

Our study indicates that most hospital and community DNS supported integrated care through management of complicated T2DM, liaising with and educating other professionals, and working independently to deliver nurse-led clinics. The latter is consistent with the move towards greater autonomy in the role. In the UK, nurse-led clinics were identified as a new development in 2008, with $90 \%$ of DNS services providing this service. ${ }^{19}$ However, we also identified specific areas for attention, in terms of the types of patients being managed by DNS, access to other professionals, 
the provision of clinics, and support for CPD, research and audit.

Although the role of the DNS is to support management of complex patients, most reported that patients with stable T2DM attend their service. DNS also highlighted ongoing issues with inappropriate referrals to secondary care. Many lacked a formal agreement on how their service operates between primary and secondary care, and a protocol to guide discharge from secondary to community care. Although most DNS had a liaison role with other care providers, referral access to specialist staff varied regionally. Space limitations, a shortfall in specialist staff and the lack of shared ICT between primary and secondary care were highlighted by DNS as barriers to service delivery. Half of DNS reported a waiting list for clinics, and the frequency varied, as did the support available in clinics from multidisciplinary professionals. These differences in clinic delivery may reflect the availability of space and staff at a given hospital or GP practice. Although most community DNS delivered community clinics, access to this service was not universal. In some areas it depended on GP willingness to engage with the integrated service, practice participation in an existing diabetes care scheme, PN availability or DNS service capacity.

Research and audit is considered a key component of the nurse specialist role nationally ${ }^{21} 31$ and internationally. ${ }^{32}$ However, as in the UK and Sweden, ${ }^{17} 1933$ we found that few DNS spend time on research or audit, lacking opportunity or support to do so. Although DNS were highly trained and experienced, as in the UK, few $(11 \%)$ had completed a master's qualification. ${ }^{34}$ Lack of support for CPD was identified as an issue in the $\mathrm{UK}^{19}{ }^{34}$ and was also highlighted by the current survey.

\section{Strengths and limitations}

This study is the first to examine the provision of DNS services nationally in Ireland. One strength is the use of a comprehensive questionnaire employed in a previous UK study, ${ }^{19}$ which was adapted for the Irish context. Although there is no definitive list of all DNS in Ireland, we enlisted the support of the IDNSA, and this increases the likelihood that all potential participants were aware of the study. All four DSIG regions and counties were well represented, and we are confident the results capture the national situation in terms of DNS services. The balance of hospital to community DNS in the study reflects the national profile of DNS. Due to the small number of nurses working in both roles, our results did not distinguish between DNS solely based in the community and those in new posts working between hospital and community. The latter group spend $80 \%$ of their time in the community and their role is likely to be very similar to community DNS. Our question on patients who attend DNS services provides some insight into whether the role aligns with the national model. However it does assume that DNS have the same understanding of what is meant by complicated and uncomplicated (stable) T2DM. A further limitation is that this question does not capture why certain patients are being seen by the DNS. For example, we do not know whether there is a process by which DNS can discharge patients who become stable, given that patients may transition from complicated to stable and vice versa. While we are lacking routinely collected administrative data on the number and nature of referrals, community DNS have begun to collect data on their activity (number of complex/stable patients seen, practices visited, GPs interested in engaging, patients were discussed with the multidisciplinary team (MDT), formal professional education sessions). These data may also be harnessed to further assess the implementation of the model.

\section{Implications}

Our study has implications for the implementation of integrated care models that rely substantially on the role of the DNS. First, the findings suggest the need for organisational and professional changes - that is, better resourcing of specialist staff, provision of dedicated space and changes in the receptiveness to the DNS role - to better enable DNS to support the integration of care as intended. Specific barriers that affect DNS service delivery (space and staff resources, inappropriate referrals to secondary care) may also not be unique to Ireland, and their implications for integrated care may be relevant for the delivery of DNS services internationally.

Second, DNS continued to manage stable T2DM and mentioned the volume of inappropriate referrals in openended comments. This appears to suggest that the model of care, where DNS primarily see complex patients, has not been fully realised. Variation in diabetes services and the capacity of primary care may mean that moving to a scenario where DNS only see complicated patients will be a gradual process. There were also regional differences in terms of patients with stable T2DM attending DNS services, which may reflect the structure of primary care locally, access to secondary care services and other specialists.

Third, while nurse-led community clinics have been implemented effectively in parts of the Netherlands as a strategy to integrate care, ${ }^{58}$ our findings suggest that local arrangements and resourcing may affect delivery. There were issues at a local level in terms of accessing DNS support through community-based clinics that have reached capacity or operate outside their catchment. Where GPs did have access, other factors (eg, being part of an existing initiative) affected eligibility. Although more work is required to fully understand how nurse-led clinics can operate effectively in this context, formal agreements and protocols to guide patient management across settings and healthcare providers are likely important. ${ }^{35}$ Without a formal structure and adequate resourcing in place, as the DNS services become oversubscribed, they may contribute to, rather than address, any existing regional variation in diabetes care.

Finally, discharge pathways to community care and formal agreements on how DNS services operate between 
the hospital and primary care did not always appear to be in place; this may be one reason why existing arrangements continue to dictate patient management across the two settings. We show that the liaison role described by DNS in this study did align with elements of international models, that is, patient case discussion ${ }^{51236}$ and care planning, ${ }^{8}$ and provision of advice, support ${ }^{513}$ and education $^{10} 13$ to other care providers. However, without formal guidance in place, DNS availability for advice and support could vary nationally. This is something that needs to be further explored.

Our study was carried out at a time of ongoing policy reform; in 2015 a new diabetes 'cycle of care' funding initiative, known as the 'cycle of care', was introduced. This scheme will for the first time nationally remunerate GPs for care of patients with stable T2DM (two structured visits of per year) who hold a general medical services card. The initiative will establish formal requirements for registering, recording and reporting processes of care (clinical parameters, routine foot screening and referral, lifestyle review) ${ }^{37}$ Payment will be made on the basis of registering eligible patients and delivering two review visits, and data will be reported/collected as per a standard proforma. While this may translate to more appropriate referrals and structured patient management, enhanced access to community resources does not form part of the initiative, and it is likely to further stretch already limited specialist resources and the demand for community DNS. Almost one-fifth of DNS surveyed will be eligible to retire in the next 10 years or fewer, which may place an additional strain on services. Our survey respondents identified the lack of DNS as a barrier to providing care. The shortfall in nurses has also been highlighted as a concern in the UK where DNS posts are stagnating. ${ }^{38}$ It is concerning that the shift of patient care to the community may continue in areas unsupported by a well-resourced multidisciplinary team. Such deficiencies will influence how successfully DNS can coordinate care and support the delivery of an integrated service.

\section{CONCLUSION}

Our results suggest that hospital and community DNS, working in a traditionally fragmented health system and against a backdrop of service variation, perform key roles to support the integration of care. Yet our findings suggest there is some regional variation in how the new model of care is being implemented, in terms of management of uncomplicated T2DM, clinic delivery and available support from multidisciplinary professionals. There are areas for improvement if the DNS role is to be used to its full potential and if a standardised model of care is to be achieved. Changes to the wider service infrastructure (resourcing, space allocation, ICT, attitudes of professionals involved) are required in order to align the health system towards the delivery of integrated care. Expanding the DNS service into the community to support primary care as an isolated strategy may be limited in its potential to fully integrate care on a national level. While this study provides a useful 'snapshot' into DNS service delivery, future qualitative work is required to explore and understand how the role supports integration and changing requirements of the service as reforms continue.

Contributors FR and JB contributed to the design of the study, conducted data collection, analysis and interpretation, drafted and revised the paper and approved the final version to be published. SMM, PMK and KM contributed to the conception and design of the study, interpretation of the data, revised the paper and approved the final version to be published.

Ethics approval Clinical Research Ethics Committee of the Cork Teaching Hospitals. Provenance and peer review Not commissioned; externally peer reviewed.

\section{Data sharing statement No additional data are available.}

Open Access This is an Open Access article distributed in accordance with the Creative Commons Attribution Non Commercial (CC BY-NC 4.0) license, which permits others to distribute, remix, adapt, build upon this work non-commercially, and license their derivative works on different terms, provided the original work is properly cited and the use is non-commercial. See: http://creativecommons.org/ licenses/by-nc/4.0/

(c) Article author(s) (or their employer(s) unless otherwise stated in the text of the article) 2017. All rights reserved. No commercial use is permitted unless otherwise expressly granted.

\section{REFERENCES}

1. Health Services Executive (HSE). Diabetes Expert Advisory Group. Kildare: Health Services Executive (HSE), 2008.

2. Kahn R, Anderson JE. Improving diabetes care: the model for health care reform. Diabetes Care 2009;32:1115-8.

3. World Health Organisation (WHO). ROADMAP. Strengthening peoplecentred health systems in the WHO European Region, 2013.

4. Russell AW, Baxter KA, Askew DA, et al. Model of care for the management of complex type 2 diabetes managed in the community by primary care physicians with specialist support: an open controlled trial. Diabet Med 2013;30:1112-21.

5. Vrijhoef HJ, Diederiks JP, Spreeuwenberg C, et al. The nurse specialist as main care-provider for patients with type 2 diabetes in a primary care setting: effects on patient outcomes. Int J Nurs Stud 2002;39:441-51.

6. Zhang J, Donald M, Baxter KA, et al. Impact of an integrated model of care on potentially preventable hospitalizations for people with type 2 diabetes mellitus. Diabet Med 2015;32:872-80.

7. Savage E, Hegarty J, Weathers E, et al. Clinical and economic systematic literature review to support the development of an Integrated Care Programme for chronic disease Prevention and Management for the Irish Health System: report prepared for Health Service Executive, 2015.

8. Ubink-Veltmaat LJ, Bilo HJ, Groenier KH, et al. Shared care with task delegation to nurses for type 2 diabetes: prospective observational study. Neth J Med 2005;63:103-10.

9. Smith S, Bury G, O'Leary M, et al. The North Dublin randomized controlled trial of structured diabetes shared care. Fam Pract 2004;21:39-45.

10. Goenka N, Turner B, Vora J; Diabetes UK Task and Finish group. Commissioning specialist diabetes services for adults with diabetes: summary of a Diabetes UK Task and finish group report. Diabet Med 2011;28:1494-500.

11. van den Berg TI, Vrijhoef HJ, Tummers G, et al. The work setting of diabetes nursing specialists in the Netherlands: a questionnaire survey. Int J Nurs Stud 2008;45:1422-32.

12. Johnson M, Goyder E. Changing roles, changing responsibilities and changing relationships: an exploration of the impact of a new model for delivering integrated diabetes care in general practice. Qual Prim Care 2005;13:856p.

13. Walsh JL, Harris BH, Roberts AW. Evaluation of a community diabetes initiative: integrating diabetes care. Prim Care Diabetes 2015;9:203-10.

14. While AFA, Mold F, multi-context A. 2010. A Multi-Method Assessment of the Contribution of Nurses to Chronic Disease Management: Report for the National Institute for Health Research Service Delivery and Organisation programme. 
15. Nocon A, Leese B. The role of UK general practitioners with special clinical interests: implications for policy and service delivery. $\mathrm{Br} \mathrm{J}$ Gen Pract 2004:54:50-6.

16. Nocon A, Rhodes PJ, Wright JP, et al. Specialist general practitioners and diabetes clinics in primary care: a qualitative and descriptive evaluation. Diabet Med 2004;21:32-8.

17. Boström E, Isaksson U, Lundman B, et al. Diabetes specialist nurses' perceptions of their multifaceted role. European Diabetes Nursing 2012;9:39-44.

18. Siminerio LM, Funnell MM, Peyrot M, et al. US nurses' perceptions of their role in diabetes care: results of the cross-national Diabetes attitudes wishes and needs (DAWN) study. Diabetes Educ 2007;33:152-62.

19. James J, Gosden C, Winocour P, et al. Diabetes specialist nurses and role evolvement: a survey by Diabetes UK and ABCD of specialist diabetes services 2007. Diabet Med 2009;26:560-5.

20. Mc Hugh S, O'Mullane M, Perry IJ, et al. Barriers to, and facilitators in, introducing integrated diabetes care in Ireland: a qualitative study of views in general practice. BMJ Open 2013;3:e003217.

21. Begley C, Murphy K, Higgins A, et al. Policy-makers' views on impact of specialist and advanced practitioner roles in Ireland: the SCAPE study. J Nurs Manag 2014;22:410-22.

22. Darker C, Bergin C, Walsh G. O'Shea B. A National Survey of Chronic Disease Management by Irish Hospital based Consultants. Dublin: Department of Public Health \& Primary Care Trinity College Dublin, 2014.

23. Health Service Executive (HSE). National Clinical Programme for Diabetes. Secondary National Clinical Programme for Diabetes, 2016. http://www.hse.ie/eng/about/Who/clinical/natclinprog/ diabetesprogramme/.

24. Mc Hugh S, O'Keeffe J, Fitzpatrick A, et al. Diabetes care in Ireland: a survey of general practitioners. Prim Care Diabetes 2009;3:225-31.

25. Mc Hugh S, O'Mullane M, Perry IJ, et al. Barriers to, and facilitators in, introducing integrated diabetes care in Ireland: a qualitative study of views in general practice. BMJ Open 2013;3:e003217.

26. Darker C, Martin C, O'Dowd T, et al; O'Shea B. A National Survey of Chronic Disease Management in Irish General Practice. Dublin:
Department of Public Health \& Primary Care, Trinity College Dublin, 2011.

27. Brennan C, Harkins V, Perry IJ. Management of diabetes in primary care: a structured-care approach. Eur J Gen Pract 2008;14:117-22.

28. Irish College of General Practitioners (ICGP). A Practical Guide to Integrated type 2 Diabetes Care, 2016.

29. McHugh S, Tracey ML, Riordan F, et al. Evaluating the implementation of a national clinical programme for diabetes to standardise and improve services: a realist evaluation protocol. Implement Sci 2016;11:107.

30. Busetto L, Luijkx K, Huizing A, et al. Implementation of integrated care for diabetes mellitus type 2 by two dutch care groups: a case study. BMC Fam Pract 2015;16:105.

31. Irish Diabetes nurse Specialist Association (IDNSA). Job Description. Secondary Job Description. http://www.idnsa.ie/about-us/jobdescription/.

32. Affara F. ICN Framework of Competencies for the nurse specialist. Geneva, Switzerland: International Council of Nurses, 2009.

33. Boström E, Hörnsten A, Lundman B, et al. Role clarity and role conflict among swedish diabetes specialist nurses. Prim Care Diabetes 2013;7:207-12.

34. Diabetes UK. Diabetes Specialist Nursing 2016 Workforce Survey, 2016.

35. Strauss A, Corbin J. Basics of qualitative research: grounded theory procedures and techniques. Newbury Park, CA: Sage Publications, 1990.

36. Borgermans L, Goderis G, Van Den Broeke C, et al. Interdisciplinary diabetes care teams operating on the interface between primary and specialty care are associated with improved outcomes of care: findings from the Leuven Diabetes Project. BMC Health Serv Res 2009;9:1-15.

37. Department of Health. Varadkar \& Lynch launch new GP Diabetes service. secondary Varadkar \& Lynch launch new GP Diabetes service. 2015 http://health.gov.ie/blog/press-release/varadkar-lynchlaunch-new-gp-diabetes-service/.

38. Diabetes UK. Diabetes Specialist Nurses position statement, 2014. 